IJPSR (2011), Vol. 2, Issue 5

INTERNATIONAL JOURNAL
PHARMACEUTICAL SCIENCES
PNID
RESEARCI

Received on 25 November, 2010; received in revised form 10 March, 2011; accepted 16 April, 2011

\title{
OCULAR DRUG DELIVERY SYSTEM: AN OVERVIEW
}

M. K. Sikandar*, P. K. Sharma and S. Visht

Department of Pharmaceutical Technology, Meerut Institute of Engineering and Technology, NH-58, Bypass Road, Bagphat crossing, Meerut, Uttar Pradesh, India

\section{Keywords:}

Ocular drug,

Nanoparticle,

Liposome

Correspondence to Author:

Mukesh Kumar Sikandar

Department of Pharmaceutical Technology, Meerut Institute of Engineering and Technology, NH-58, Bypass Road, Bagphat crossing, Meerut, Uttar Pradesh, India

\section{ABSTRACT}

The scientist faced many challenges in Ocular drug delivery system due to unique anatomy and physiology of eye. In ocular drug delivery system there are two types of barriers static and dynamic barrier. Static barriers consist of different segment of eye such as cornea, sclera, retina and blood- retinal barriers. In other way dynamic barriers consists choroidal and conjunctival blood flow, lymphatic clearance, and tear dilution. These both barriers affect the bioavailability of drugs. In recent year some new concept of drug delivery such as iontophoresis, liposome bioadhesive gels, ocular insert, contact lenses etc has been developed to overcome problems associated by static and dynamic barriers These formulation based approaches have high capacity to carry maximum concentration of drug at targeted site of eye. 
INTRODUCTION: In ocular drug delivery system, there is a main problem of rapid and extensive elimination of conventional eye drops from the eye ${ }^{1-3}$. This problem results in extensive loss of drug. Only a few amount of drug penetrates the corneal layer and reached to internal tissue of eye ${ }^{4-5}$. The main region of drug loss includes lachrymal drainage and drug dilution by tears ${ }^{6}$. This superfluity reduces the ocular bioavailability and lead to unwanted toxicity and side effect.

The following characteristics are required to optimize ocular drug delivery systems ${ }^{7}$.

- A good corneal penetration.

- A prolonged contact time of drug with corneal tissue.

- Simplicity of installation and removal for the patient.

- A non-irritative and at ease form (the viscous solution should not irritate lachrymation and reflex flashing).

- Appropriate rheological properties and concentration of viscolyzer.

Over last two decades valuable attention is to be made on development of sustained and controlled release drug delivery system. The aim of such system based on localization on site of action so as to avoid the dose frequency and improvement in the drug effectiveness.

\section{Drug delivery to eye:}

Anatomical and Physiological features of the Eye: The eye is a very sensitive organ of the body. There are many anatomical and physiological features which affect the administered drug. These are as follows:

- Blinking of eye

- Tear secretion

- Nasolachrimal drainage

Upon reflex blinking lid closure provides protection against external problems. Tears wash the surface of eye. It contains lysozyme and immunoglobulin which exert an anti-infectious activity to eye. The lachrymal fluid drained out through nasolachrimal rout, pharynx and esophagus. In addition binding of drug to conjunctival mucin and tears proteins also inactivate the drug ${ }^{8-10}$.

Corneal Absorption: In terms of corneal absorption of drug, the cornea consists of three layers which are responsible for its poor permeability ${ }^{11}$. These are as follows:

1. The superficial layer of epithelium, which is lipophilic in nature.

2. The stroma, which is hydrophilic in nature this layer is mostly responsible for thickness of cornea.

3. The inner endothelium consisting of a single layer of trampled epithelium like cells. Since, the cornea has both hydrophilic and lipophilic structures. It presents an efficient obstruction to the absorption of both hydrophilic and lipophilic compounds.

Some formulation based approaches used for improvement of ocular bioavailability of drugs. The duration of ophthalmic drug can be divided in to two categories. The first category based on controlled release and continuous delivery of drugs. The second category based on prevention of pre-corneal loss of drug (fig. 1). Some necessities of controlled drug delivery system to eye are as follows:

- To provide sustained and controlled drug delivery.

- To improve bioavailability by increasing corneal contact time of the drug.

- To minimize the side effects produced by conventional systems.

- To give targeting within the ocular globes so as to put off the loss of drugs.

- To provide better accommodation of the delivery system in the eye so that the loss to other tissues besides cornea is disallowed. 


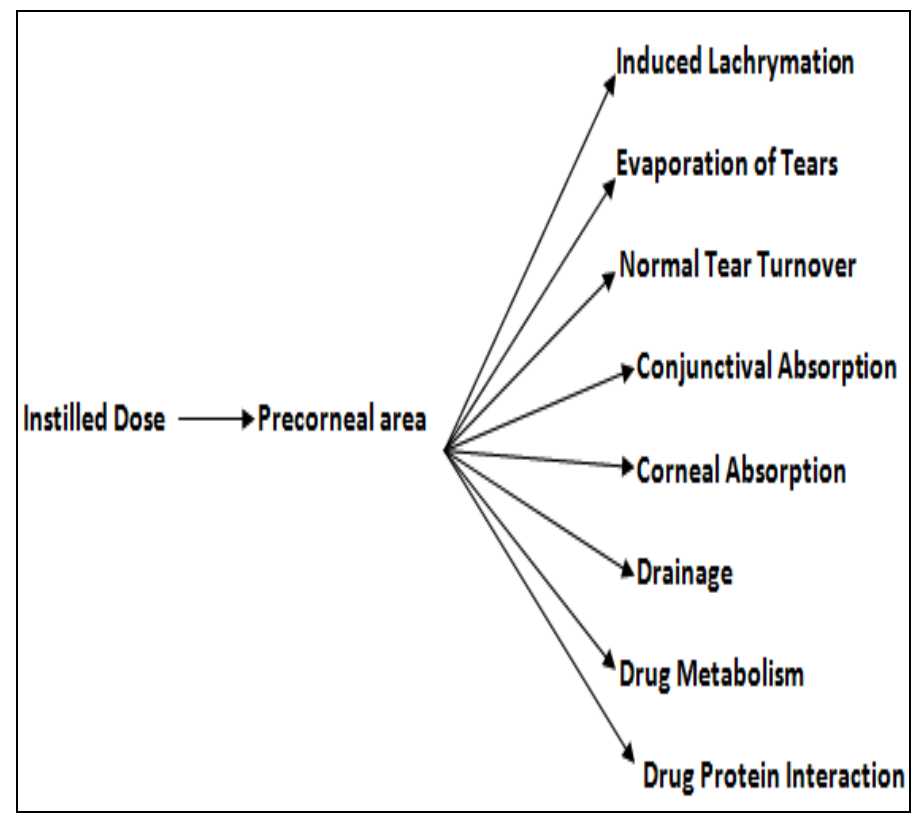

FIG. 1: DRUG ELIMINATION PATHWAYS FROM THE PRECORNEAL AREA

Eye Penetration of Drugs Administered Locally: In ocular drug delivery, if drug is not act on outer surface of eye then the active drug substance has to enter the internal tissue of eye. The most important route for drug delivery is transcorneal but non corneal route has also contributed significant to bioavailability of some drugs such as insulin and timolol ${ }^{12}$. In other way sclera has high permeability for some $\beta$ - blockers ${ }^{13}$. In humane eye hydrophilic-lipophilic nature of cornea indicates the absorption of active ingredient depends on both hydrophilic-lipophilic nature of drug. Secretion of tear spread by blinking of eyelids and keeps the cornea clean, moist and healthy.

Eye Penetration of Systemically Administered Drugs: Because of blood-eye-barriers it is interested to reflect penetration of the systematic administration of anti- infectious and anti- inflammatory drugs. The ciliary epithelium produces aqueous humor. These acts as ultra filtrate and restrict the entry of macro molecules such as antibiotics and plasma proteins. Drug delivery to the posterior site and retina is very difficult because of blood-retina barriers complicated by high viscosity, prevents diffusion of drugs in the posterior pole of the eye.
Drug Delivery to the Internal Regions of the Eye: The aim of pharmacotherapeutics is to treat a disease in a reliable and conventional approach. A supposition is made that a correspondence exists between the concentration of a drug at its proposed site of action and the consequential pharmacological effect. Following factors have to be considered during drug delivery to the intraocular tissues.

- Pinpoint the pharmacodynamic action at the eye and lessen drug action on other tissues.

- Traverse the blood-eye fence (systemic to ocular) or cornea (external to ocular) to get to the site of action.

- Lengthen the duration of drug action such that the rate of recurrence of drug administration can be condensed.

Pre-Ocular Retention: It has been anticipated that the human eye can embrace just about $35 \mu l$ of an ophthalmic solution without dribble over or spillage at the outer angle ${ }^{14}$, while the amount delivered by most marketable ophthalmic eye drop dispensers is more or less than $45 \mu \mathrm{l}$. Thus a large fraction of the drug is shattered due to administration of a surfeit volume. Following the removal of the surfeit solution from the front of the eye, a second mechanism of clearance prevails. The eye has a competent system for tear turnover $(1 \mu \mathrm{l} / \mathrm{min})$. The two mechanisms of clearance result in a biphasic profile for an instilled solution with a quick initial clearance phase due to exclusion of surfeit fluid followed by a slower second phase due to tear turnover ${ }^{15}$.

Recent advances in ocular drug delivery system: In 1970s a wide-ranging works has done by researchers in ocular drug delivery system. The approaches attempted by researchers in early stage are divided in to two categories: first is enhancement of bioavailability and second is controlled release drug delivery system. Later than various types of inserts, contact lenses and nanoparticles were attempted but some approaches dropped after an initial exploration. 
Consequently some approaches were vastly successful and led to marketed product.

\begin{tabular}{|c|c|c|}
\hline $\begin{array}{l}\text { Brand } \\
\text { Name }\end{array}$ & Dosage Form & Uses \\
\hline Acuvail & $\begin{array}{l}4.5 \mathrm{mg} / \mathrm{ml} \text { ketorolac tromethamine } \\
\text { solution }(0.45 \%) \text { in a single-use vial. }\end{array}$ & Cataract surgery \\
\hline Alocril & $\begin{array}{l}2 \% \text { is a clear, yellow, sterile } \\
\text { solution. }\end{array}$ & $\begin{array}{c}\text { Allergic } \\
\text { conjunctivitis }\end{array}$ \\
\hline Elestat & $\begin{array}{l}0.05 \% \text { epinastine } \mathrm{HCl} \text { ophthalmic } \\
\text { solution. }\end{array}$ & $\begin{array}{c}\text { Allergic } \\
\text { conjunctivitis }\end{array}$ \\
\hline Ozurdex & $\begin{array}{l}0.7 \mathrm{mg} \text { dexamethasone intravitreal } \\
\text { ocular implant. }\end{array}$ & $\begin{array}{l}\text { Retinal vein } \\
\text { occlusion }\end{array}$ \\
\hline Pred Forte & $\begin{array}{l}1 \% \text { prednisolone acetate } \\
\text { ophthalmic suspension, USP. }\end{array}$ & $\begin{array}{c}\text { Bulbar } \\
\text { conjunctiva }\end{array}$ \\
\hline Trivaris & $\begin{array}{l}80 \mathrm{mg} / \mathrm{ml} \text { triamicinolone acetonide } \\
\text { injectable suspension. }\end{array}$ & $\begin{array}{l}\text { Sympathetic } \\
\text { ophthalmia }\end{array}$ \\
\hline Zymar & $\begin{array}{l}0.3 \% \text { gatifloxacin ophthalmic } \\
\text { solution. }\end{array}$ & $\begin{array}{l}\text { Bacterial } \\
\text { conjunctivitis }\end{array}$ \\
\hline Zymaxid & $\begin{array}{l}0.5 \% \text { gatifloxacin ophthalmic } \\
\text { solution. }\end{array}$ & $\begin{array}{c}\text { Bacterial } \\
\text { conjunctivitis }\end{array}$ \\
\hline
\end{tabular}

Nanoparticles and Microparticles: Particulate polymeric drug delivery systems include micro and nanoparticles. The superior size of microparticles for ophthalmic administration is regarding 5-10 mm, above this size, a scratching sensation in the eye can result after ocular application. Microspheres and nanoparticles signify hopeful drug carriers for ophthalmic application. The drug binding is depends on the physicochemical properties of the nano- or micro-particle polymer. After finest drug binding to these particles, the drug absorption in the eye is enhanced extensively in comparison to eye drops. Particulates such as nanocapsules, nanoparticles, nanosuspensions etc are used to improve the bioavailability of ocularly applied drugs ${ }^{17}$.

Artificial Tear Inserts: In 1981 Merck, Sharp and Dohme was developed a device for sustained release known as artificial tear. Commercially Lacrisert is available in the market. It contains hydroxyl propyle cellulose without preservatives used in the treatment of dry eye ${ }^{18}$.

Ocular Inserts: In traditional system of drug delivery such as suspension, aqueous solution and ointment have so many disadvantages. Ocular inserts minimize the problem occur in traditional system. These are solid dosage form have high capacity to carry required concentration of drug in to targeted tissue. Some examples of ocular inserts are- Dexamethasone, Pilocarpine nitrate, Tropicamide and Timolol Maleate 19

Advantages of ocular inserts: Ocular inserts offer several advantages ${ }^{20-22}$, which can be summarized as follows:

- Diminution of complete absorption (which occurs freely with eye drops via the nasolachrimal canal and nasal mucosa);

- Possibility of releasing drugs at a slow, steady rate;

- Improved ocular habitation, hence a extended drug activity and a elevated bioavailability with respect to usual vehicles;

- correct dosing (converse to eye drops that can be shockingly instilled by the patient and are partially vanished after administration, each insert can be made to contain a accurate dose which is fully retained at the administration site);

- Improved shelf life with reverence to aqueous solutions;

- Better patient compliance, resulting from a abridged frequency of administration and a lesser incidence of visual and systemic sideeffects; 
- Exclusion of preservatives, thus plummeting the risk of sensitivity reactions;

- Possibility of incorporating various novel chemical/technological approaches.

Disadvantages of ocular inserts: The disadvantages of ocular inserts are as follows:

- A principal disadvantage of ocular inserts resides in their 'solidity', i.e., in the fact that they are felt by the (often too sensitive) patients as a superfluous body in the eye. This may constitute a redoubtable physical and psychological obstruction to user recognition and compliance.

- Their movement in the region of the eye, in rare instances, the simple elimination is made more complicated by unnecessary movement of the insert to the upper fornix.

Contact Lenses: Contact lenses are the new concept of ocular drug delivery. In this system the contact lenses saturated by drug and placed in to eye. The drug release from these lenses takes a long period of time. The hydrophilic contact lens widely used. They soaked in drug solvent and absorb drug (water soluble drugs). In the humane eye Fluorescein drug administered by using bionite lens which contain 2hydroxy ethyl methylacrylate as a hydrophilic polymer. They increase the penetration rate of Fluorescein drug. ${ }^{23}$

Ocular lontophoresis: Lantophoresis is a new concept in ocular drug delivery system in which charged drug molecules are used. Positive charge drug molecules were driven into the tissue at anode and negative charge drug molecule driven respectively at cathode. Ocular lantophoresis is safe, fast and easy. It is also proficient to hold high concentration of drugs at targeted tissue. Application of drugs such as antibiotics and anti-inflammatory by using lontophoresis, increase the antibacterial activity and reduced the side effect. ${ }^{24}$
Liposome: Liposome is phospholipids-lipid vesicles for targeting drugs to the specific sites in the body. They give proscribed and selective drug delivery to eye and enhanced bioavailability of drug. Their probable in ocular drug delivery appears greater affinity to lipophilic than hydrophilic compounds. Liposomes propose the advantage of being entirely biodegradable and moderately safe but are fewer stable than particulate polymeric drug delivery systems. Liposomes were found to be a latent delivery system for administration of a number of drugs to the eye ${ }^{25}$ e.g. Penicillin $G$ and Tropicamide Depending upon their size and structure, liposomes are classified as ${ }^{26}$;

1. Multilamellar vesicles (MLV): $5-20$ bilayers of lipids and diameter more than $5000 \mathrm{~nm}$.

2. Oligolamellar vesicles (OLV): $2-5$ bilayers of lipid and diameter 100-1000nm.

3. Multivascular vesicles (MVV): Diameter more than $1000 \mathrm{~nm}$.

4. Unilamellar vesicles (ULV): single bilayers of lipids

These may be further classified on the basis of their size into

a) SUV (smaller unilamellar vesicles) of size 2040nm.

b) MUV (medium unilamellar vesicles) of size 40$80 \mathrm{~nm}$.

c) LUV(Larger unilamellar vesicles) of size 100$1000 \mathrm{~nm}$

d) GUV (Giant unilamellar vesicles) of size greater than $1000 \mathrm{~nm}$.

Liposome possesses special characteristics such as:

- Biodegradable and harmless.

- Do not interact with drug or change its activity

- Controlled hydration.

- Controlled drug delivery rate.

- Capability to integrate both water and oil soluble drugs. 
- Ability to shield labile compounds.

- Accessible in range in size.

Collagen Shield: Collagens have superb biocompatibility and safety due to its biological characteristics and mainly used in medical application because biodegradability and weak antigenecity. Collagen shield was first prepared from procine sclera tissues because they bear a collagens parallel composition to that of humane eye. The shields are hydrated before the insertion into the eye; typically the drug is loaded into the drug solution for a period of time prior to application.

Collagen shield often produce some discomfort and blurred vision and are not fit for each patient. For enhancement of this problem, Kaufman discovered a new concept of drug delivery by mixture of collagen shield particles and contact lenses named collasomes. Collasomes could be instilled beneath the eyelid and reduce the blurred vision problem ${ }^{27}$.

Mucoadhesive Dosage Forms: Mucoadhesive dosage forms for ocular delivery still poses numerable challenges ${ }^{28}$. This approach relies on vehicles containing polymers which will attach, via noncovalent bonds, to conjunctival mucin. Mucoadhesive polymers are typically macromolecular hydrocolloids with several hydrophilic functional groups, such as carboxyl-, hydroxyl-, amide and sulphate, competent of establishing electrostatic interactions.

The bioadhesive dosage form showed more bioavailability of the drug than those of conventional dosage forms. The result is evaluated of polyacrylic acid as a bioadhesive polymer on the ocular bioavailability of timolol. It was also used in the enhancement of ocular bioavailability of progesterone 29 .

Microemulsion: Microemulsion has native properties and specific structures. They are prepared by auto emulsification and straightforwardly sterilized. These preparations have high capability of dissolving the drugs and good stability. Due to these properties it has good bioavailability. The mechanism of action of drug is absorption. Microemulsion contains nanodroplets in interior phase which reserve the drug substance on outer surface of cornea, and reduced the drainage of drugs ${ }^{30}$.

Solutions and Suspensions: These are liquid preparation contain drug substances which are used in ocular drug delivery. The drug substance must be active on surface of eye or internal region of eye after passage through cornea or conjunctiva. These preparations also have some disadvantages such as poor bioavailability and poor stability. The problems related to stability, bioavailability and ocular retention time of solution formulation are solved by extensive work done by researchers by enhancing viscosity, using preservatives and changing the $\mathrm{pH}$ of these formulations ${ }^{31-32}$.

Sol to Gel Systems: In 1980s a new concept producing a gel in situ was recommended by researchers. This concept of drug delivery to eye is widely used because it increases the viscosity and reduced the drainage of drug from cornea. Therefore the bioavailability of drug automatically increased. The in-situ gelling system can be influenced by temperature, $\mathrm{pH}$ or ion activation. In experimental investigation of rabbit eye investigator found the in-situ gelling system gives better and prolong of drug compare to the conventional eye drops ${ }^{33}$.

CONCLUSION: The extensive work in ocular drug delivery during the earlier period. It has been intend, to extend the residence time of topically applied drugs in the corneal and conjunctiva section. Some new approaches such as nanoparticles, liposome, contact lenses, ocular inserts, collagen shield, in situ activated gel formation, non corneal route of ocular drug diffusion, and nanoparticles- based polymeric solutions and gels are being developed by the pharmaceutical science. 


\section{REFERENCES:}

1. Joshi $A$, Ding $S$ and Himmelstein $\mathrm{KJ}$ : Reversible gelatin composition and method of use. US Patent No. 5,252,318; October 121993.

2. Kumar S, Haglund $\mathrm{BO}$ and Himmelstein KJ: In situ forming gels for ophthalmic drug delivery. Journal of Ocular Pharmacology. 1994; 10:47-56.

3. Le Bourlais C, Aear L, Zia H, Sado PA, Needham T and Leverge R: Ophthalmic drug delivery systems recent advances. Prog Retinal Eye Research. 1998; 17:33-58.

4. Patton TF and Robinson JR: Quantitative precorneal disposition of topically applied pilocarpine nitrate in rabbit eyes. Journal of Pharmaceutical Science 1976; 65: 1295-1301.

5. Wood RW, Li VHE, Kreuter J and Robinson JR: Ocular disposition of polyhexyl-2 cyano [3-14C] acrylate nanoparticles in albino rabbits International Journal of Pharmaceutical science 1985; 23:175-183.

6. Lee VHL and Robinson JR: Mechanistic and quantitative evaluation of precorneal pilocarpine in albino's rabbit. Journal of Pharmaceutical Science 1979; 68:673-684.

7. Keister JC, Cooper ER, Missel PJ, Lang JC and Hager DF: Limits on optimizing ocular drug delivery Journal of Pharmaceutical Science 1991; 80:50-53.

8. Lee VHL: Precorneal, corneal and postcorneal factors. In AK Mitra, Ophthalmic Drug Delivery Systems. Marcel Dekker, New York, Edition 1, 1993:59:81.

9. Tang NEML, Zuure PL, Pardo RD, Keizer RJW and Van Best JA: Re.ex lacrimation in patients with glaucoma and healthy control subjects by uorophotometry. Invest Ophthalmologic Visual Science 2000; 41: 709-714.

10. White WL, Glover AT and Buckner AB: Effect of blinking on tear elimination as evaluated by dacryoscintigraphy Ophthalmology. 1991; 98: 367-369.

11. Stewart WC: Timolol hemihydrate a new formulation of timolol for the treatment of glaucoma. Journal of Ocular Pharmacology Therapeutic 1996; 12: 225:236.

12. Ahmed I and Patton TF: Importance of non-corneal absorption route in topical ophthalmic drug delivery. Invest Ophthalmologic Visual Science. 1985; 26: 584-587.

13. Schoenwald RD, Deshpande GS, Rethwisch DG and Barfknecht CF: Penetration into the anterior chamber via the conjunctival scleral pathway. Journal of Ocular Pharmacologic Therapeutics 1997; 13: 41-59.

14. Mishima S, Gasset A, Klyce SD and Baum JL: Determination of tear volume and tear flow. Invest Ophthalmologic 1966; 5: 264.

15. Chrai SS, Patton TF, Mehta A and Robinson JR: Lachrymal and instilled fluid dynamics in rabbit eye. Journal of Pharmaceutical Science 1973; 62:1112-1121.

16. www.allergan.com.
17. Swanson AA, Jeter DJ and Tucker P: Ophthalmic vehicles II Comparison of ointment and polyvinyl alcohol $1.4 \%$. Ophthalmologic 1970; 160:265-70.

18. La Motte J, Grossman E and Hersch J: The efficacy of cellulosic ophthalmic inserts for treatment of dry eye. Journal of American Ophthalmologic Association 1985; 56:298-302.

19. Lerman S, Davis $P$ and Jackson WB: Prolonged release hydrocortisone therapy. Journal of Ophthalmology 1973; 8:114-8.

20. Chien YW: Ocular drug delivery and delivery systems. In Novel drug delivery systems. Marcel Dekker, New York, Edition 2, 1992: 269-70.

21. Saettone MF and Salminen L: Ocular inserts for topical delivery. Advance Drug Delivery Review 1995; 16:95-106.

22. Khar RK, Vyas SP: Targeted and Controlled drug delivery novel carrier systems. CBS Publishers and Distributors, New Delhi, Edition 1, 2002: 384.

23. Vadnere $\mathrm{M}$, Amidon $\mathrm{G}$, Lindenbaum $\mathrm{S}$ and Haslam $\mathrm{JL}$ : Thermodynamic studies on the gel-sol transition of some pluronic polyols. International Journal of Pharmaceutical science $1984 ; 22: 207-18$

24. Rootman DS, Jantzen JA, Gonzalez JR, Fischer MJ, Beuerman R and Hill JM: Pharmacokinetics and safety of transcorneal iontophoresis of tobramycin in the rabbit. Ophthalmologic Visual Science 1988; 29:1397-401.

25. Nagarsenkar MS, Vaishali $Y$, Londhe and Nadkarni GD: Preparation and evaluation of liposomal formulations of tropicamide for ocular delivery. International Journal of Pharmaceutical 1999; 190:63- 71.

26. Brahmankar D.M. and Jaiswal B.S: Biopharmaceutics and Pharmacokinetic. Vallabh Prakashan. 2009 ; 2: 481-483.

27. Kaufman $\mathrm{HE}$, Steinemann $\mathrm{TL}$, Lehman $\mathrm{E}$, Thompson HW, Varnell ED and Jacob-Labarre T, Journal of Ocular Pharmaceutical 1994;10:17-27.

28. Mitra AK. Ophthalmic drug delivery system. Marcel Dekker. 2nd Ed. In: Ocular Penetration Enhancers 2003;130:

29. Hui HW and Robinson JR: Ocular Delivery of Progesterone using a bioadhesive polymer. International Journal of Pharmaceutical I985; 26:203.

30. Vandamme TF: Microemulsions as ocular drug delivery systems. Prog Retina Eye Research 2002; 21:15-34.

31. Mueller WH and Deardroff DL: The effect of methyl cellulose on the penetration of Homatropine hydro bromide through the cornea. Journal of American Pharmaceutical Association 1956; 45:334-41.

32. Krishna $\mathrm{N}$ and Brown F: Polyvinyl alcohol as an ophthalmic vehicle. American Journal of Ophthalmologic 1964; 57:99-106.

33. Middleton DL and Robinson JR: Design and evaluation of an ocular bioadhesive delivery system. STP Pharmaceutical Science 1991; 1:200-6. 